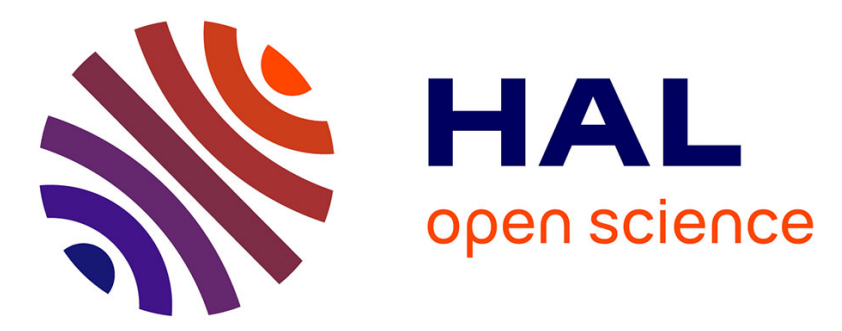

\title{
Nitrogen-containing Anions and Tholin Growth in Titan's Ionosphere: Implications for Cassini CAPS-ELS Observations
}

David Dubois, Nathalie Carrasco, Jérémy Bourgalais, Ludovic Vettier, Ravindra T. Desai, Anne Wellbrock, Andrew J. Coates

\section{To cite this version:}

David Dubois, Nathalie Carrasco, Jérémy Bourgalais, Ludovic Vettier, Ravindra T. Desai, et al.. Nitrogen-containing Anions and Tholin Growth in Titan's Ionosphere: Implications for Cassini CAPS-ELS Observations. The Astrophysical journal letters, 2019, 872 (2), pp.L31. 10.3847/20418213/ab05e5 . insu-02054827

\section{HAL Id: insu-02054827 https://hal-insu.archives-ouvertes.fr/insu-02054827}

Submitted on 13 Mar 2019

HAL is a multi-disciplinary open access archive for the deposit and dissemination of scientific research documents, whether they are published or not. The documents may come from teaching and research institutions in France or abroad, or from public or private research centers.
L'archive ouverte pluridisciplinaire HAL, est destinée au dépôt et à la diffusion de documents scientifiques de niveau recherche, publiés ou non, émanant des établissements d'enseignement et de recherche français ou étrangers, des laboratoires publics ou privés. 


\title{
Nitrogen-containing Anions and Tholin Growth in Titan's Ionosphere: Implications for Cassini CAPS-ELS Observations
}

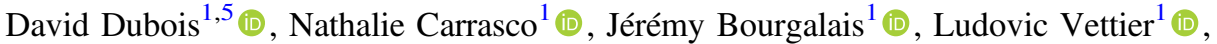 \\ Ravindra T. Desai ${ }^{2}$ (1), Anne Wellbrock ${ }^{3,4}$, and Andrew J. Coates ${ }^{3,4}$ (1) \\ ${ }^{1}$ LATMOS/IPSL, UVSQ Université Paris-Saclay, UPMC Univ. Paris 06, CNRS, Guyancourt, France; david.f.dubois@ nasa.gov \\ ${ }^{2}$ Blackett Laboratory, Imperial College London, London, UK \\ ${ }^{3}$ Mullard Space Science Laboratory, University College London, Holmbury St. Mary, Dorking, Surrey RH5 6NT, UK \\ ${ }^{4}$ Centre for Planetary Science at UCL/Birkbeck, London, Gower Street, London WC1E 6BT, UK \\ Received 2018 December 25; revised 2019 February 8; accepted 2019 February 11; published 2019 February 22
}

\begin{abstract}
The Cassini Plasma Spectrometer (CAPS) Electron Spectrometer (ELS) instrument on board Cassini revealed an unexpected abundance of negative ions above $950 \mathrm{~km}$ in Titan's ionosphere. In situ measurements indicated the presence of negatively charged particles with mass-over-charge ratios up to $13,800 \mathrm{u} / \mathrm{q}$. At present, only a handful of anions have been characterized by photochemical models, consisting mainly of $\mathrm{C}_{n} \mathrm{H}^{-}$carbon chain and $\mathrm{C}_{n-1} \mathrm{~N}^{-}$ cyano compounds $(n=2-6)$; their formation occurring essentially through proton abstraction from their parent neutral molecules. However, numerous other species have yet to be detected and identified. Considering the efficient anion growth leading to compounds of thousands of $u / q$, it is necessary to better characterize the first light species. Here, we present new negative ion measurements with masses up to $200 u / q$ obtained in an $\mathrm{N}_{2}: \mathrm{CH}_{4}$ dusty plasma discharge reproducing analogous conditions to Titan's ionosphere. We perform a comparison with highaltitude CAPS-ELS measurements near the top of Titan's ionosphere from the T18 encounter. The main observed peaks are in agreement with the observations. However, a number of other species (e.g., $\mathrm{CNN}^{-}, \mathrm{CHNN}^{-}$) previously not considered suggests an abundance of N-bearing compounds, containing two or three nitrogen atoms, consistent with certain adjacent doubly bonded nitrogen atoms found in tholins. These results suggest that an $\mathrm{N}$-rich incorporation into tholins may follow mechanisms including anion chemistry, further highlighting the important role of negative ions in Titan's aerosol growth.
\end{abstract}

Key words: astrochemistry - ISM: molecules - methods: laboratory: molecular - planets and satellites: atmospheres - planets and satellites: individual (Titan)

\section{Introduction}

Ubiquitous anion chemistry present in circumstellar envelopes, clouds in the interstellar medium (ISM), planetary atmospheres, and cometary comae has for $\sim 4$ Gya relied on the simplest anion found in space: $\mathrm{H}^{-}$, formed through radiative electron attachment (REA). Necessary for the formation of $\mathrm{H}_{2}$ (see Millar et al. 2017 for a detailed review and references therein), $\mathrm{H}^{-}$proceeds through e.g., electron attachment (EA), REA, or dissociative electron attachment (DEA) mechanisms. To date, $\mathrm{C}_{8} \mathrm{H}^{-}$is the largest carbon-chain anion detected in the ISM, i.e., the TMC-1 molecular cloud (Brünken et al. 2007). Regarding planetary atmospheres, however, the ionosphere of Titan, Saturn's largest moon, stands out as containing an abundance of unsuspected negative ions above $950 \mathrm{~km}$ (Coates et al. 2007; Waite et al. 2007; Ågren et al. 2012). Using Cassini Plasma Spectrometer Electron Spectrometer instrument (CAPS-ELS; in electron spectrometer mode) measurements from 16 passes, Coates et al. (2007) revealed the presence of anions with mass-to-charge ratios up to 10,000 , as well as latitude and altitude variations (Coates et al. 2009).

The first photochemical model accounting for ionospheric negative ion species was subsequently investigated by Vuitton et al. (2009), and focused on 11 low-mass negative ions. In spite of the lower-mass resolution of CAPS, the isoelectronic series $\mathrm{C}_{2 n+1} \mathrm{~N}^{-}$, viz. $\mathrm{CN}^{-}, \mathrm{C}_{3} \mathrm{~N}^{-}$, and $\mathrm{C}_{5} \mathrm{~N}^{-}$were predicted to

\footnotetext{
5 Present addresses: NASA Ames Research Center, Space Science \& Astrobiology Division, Astrophysics Branch, Moffett Field, CA, USA, Bay Area Environmental Research Institute, Petaluma, CA, USA.
}

be the three most abundant negative ions with a density peak near $1000 \mathrm{~km}$ (Vuitton et al. 2009). More recent analyses by Desai et al. (2017) additionally revealed the contribution of carbon-chain anions containing ethynyl groups $\left(-\mathrm{C}_{n} \mathrm{H}\right.$, with $n=2,4,6$ ), which could not be differentiated from the cyanocontaining species. The location of peaks up to $165 \mathrm{u} / q$ were statistically constrained, and an anti-correlation was found between the depletion of low-mass anions and the growth of larger ones $<1100 \mathrm{~km}$. These results suggested that low-mass anions may contribute to the growth of larger organic species with decreasing altitude, consistent with $\mathrm{CN}^{-} / \mathrm{C}_{3} \mathrm{~N}^{-}$and $\mathrm{C}_{2} \mathrm{H}^{-} / \mathrm{C}_{4} \mathrm{H}^{-}$growth patterns. Nonetheless, only a handful of anions are presently characterized. An abundance of light and heavier species remains unidentified. Furthermore, Lavvas et al. (2013) studied aerosol growth by modeling the interaction of the aerosols in Titan's ionosphere through mass transfer between positively charged and negatively charged particles.

Currently, three photochemical modeling studies account for negative ions (Vuitton et al. 2009, 2018; Dobrijevic et al. 2016 and Mukundan \& Bhardwaj 2018). In the former studies, ionpair formation, DEA, REA, and DEA of supra-thermal electrons with nitriles such as $\mathrm{HCN}$ were found to be significant production pathways in the first steps of the anion chemistry.

Recently, Mukundan \& Bhardwaj (2018; and since Vuitton et al. 2018) revisited these density profiles for Titan's dayside T40 flyby with updated cross sections and reaction rate coefficients. In agreement with prior studies, $\mathrm{CN}^{-}$was found to be the dominant anion $\left(\sim 5 \times 10^{-1} \mathrm{~cm}^{-3}\right.$ at $\left.1015 \mathrm{~km}\right)$ due to 
abundant $\mathrm{HCN}$. However, the second most abundant anion was either $\mathrm{H}^{-}$or $\mathrm{C}_{3} \mathrm{~N}^{-}$, with an inversion near the ionospheric peak (Mukundan \& Bhardwaj 2018).

Laboratory experiments have thus far mainly explored specific anion growth routes involving $\mathrm{CN}^{-}$(Zabka et al. 2012; Biennier et al. 2014) and $\mathrm{C}_{3} \mathrm{~N}^{-}$(Bourgalais et al. 2016). Wang et al. (2015, 2016) studied pathways involving negatively charged polyaromatic hydrocarbons with $\mathrm{N}$ and $\mathrm{O}$ atoms, and Horvath et al. (2010a) measured light negative ions in a high-pressure point-to-plane $\mathrm{N}_{2}: \mathrm{CH}_{4}$ :Ar corona discharge. At present, more laboratory experiments are needed to investigate anion growth routes and composition in plasma conditions. Based on current and future experimental results, a better understanding of the anion gas phase precursors will lead to a clearer overall picture of how Titan's aerosols are formed in the upper atmosphere.

Here, we report mass spectrometry measurements performed in Titan-like simulations in order to assess light and intermediate anion precursors to tholin formation and subsequent growth. We have carried out negative ion measurements with mass detections of up to $200 \mathrm{u} / q$ in $\mathrm{N}_{2}: \mathrm{CH}_{4}$ mixtures representative of Titan's ionospheric conditions. The spectra obtained are compared with CAPS-ELS observations obtained during the T18 encounter in the 1-200 $\mathrm{u} / \mathrm{q}$ range. The role of the light and intermediate anion species and implications for tholin growth is also discussed.

\section{Methods}

In order to simulate analogous conditions found in Titan's ionosphere, we used the PAMPRE experiment (Szopa et al. 2006), a radio-frequency (RF) dusty plasma generated at $13.56 \mathrm{MHz}$. The RF source $(30 \mathrm{~W})$ delivers a capacitively coupled plasma located between two electrodes, with a constant gas pressure of $\sim 1$ mbar. The pressure here is higher than in Titan's ionosphere in order to compensate for the low collision frequency in the plasma and accelerate the gas product yield. The plasma was in a grid-free configuration (see Dubois et al. 2019). The presence of a confining grid prevents the obstruction of the Quadrupole Mass Spectrometer (QMS).

Negative ion measurements were carried out with a Hiden Analytical EQP 200 QMS in contact with the plasma with an extraction potential of $+190 \mathrm{~V}$, through a $100 \mu \mathrm{m}$ pinhole. The ions encountered a series of pre-optimized lenses and were guided through the ion optics until they reached an energy filter and finally a Secondary Electron Multiplier detector at $1800 \mathrm{~V}$. We used a $200 \mathrm{~ms} / u$ dwell time for mass analysis at $1 u$ steps over 1-200 $u / q$ while accumulating signal over 325 scans. Signal accumulation is necessary due to the low intensity of negative ions. Spectra are normalized over the highest intensity (at $26 \mathrm{u} / \mathrm{q}$ ) and only actual signal above the background electrical noise $\left(>10^{-3}\right)$ is plotted.

\section{Results}

\subsection{Main Anions and CAPS-ELS Observations}

CAPS consisted of three sensors, one being ELS. The ELS was a top-hat electrostatic analyzer initially designed to measure differential electron velocity distributions. Measurements of negative ions in Titan's cold ionosphere were obtained while the spacecraft was in the ram direction. With Cassini at supersonic velocities $\left(\sim 6 \mathrm{~km} \mathrm{~s}^{-1}\right)$, negative ions appear as sharp beam features seen by ELS (Coates et al. 2007). The CAPS actuator therefore swept across the field of view in the spacecraft's ram direction, resulting in multiple negative ion spectra during flybys. The observed ram energyper-charge can be converted into mass-per-charge knowing the relative spacecraft speed and taking into account a spacecraft potential correction, assuming singly charged anions. This conversion theoretically enables the identification of particles up to $150,000 \mathrm{u} / \mathrm{q}$ (Coates et al. 2007), although to date $10^{4} \mathrm{u} / \mathrm{q}$ represents the highest anion mass observed at Titan. The analyzer had an energy bandwidth $\Delta E / E=16.7 \%$, corresponding to the energy resolution of the sensor. This roughly corresponds to a mass resolution of $\sim 6$. By contrast, the ion mass spectrometer used in this study has a mass resolution of 100 at $100 \mathrm{u} / q$, enabling us to distinguish more species in the laboratory.

Figure 1 shows a comparison between the experimental spectrum and CAPS-ELS measurements taken during the T18 encounter at $\sim 1235 \mathrm{~km}$. This flyby occurred on 2006 September 23 over Titan's north polar region, entering on the nightside and exiting on the dayside, with a closest approach near the terminator. Background electron counts are removed by subtracting averaged counts from non-ram pointing anodes (Coates et al. 2007; Wellbrock et al. 2013; Desai et al. 2017).

The experimental spectrum was taken in an $\mathrm{N}_{2}: \mathrm{CH}_{4} 95: 5 \%$ plasma (black, bottom panel) with the major predicted anions. Approximately eight groupings up to $120 \mathrm{u} / \mathrm{q}$ in the experimental spectrum are found (Table 1), with main peaks alternatively separated by 15 and $9 u$ from 26 to $74 u / q$. Although few ions are detected between 120 and $150 \mathrm{u} / \mathrm{q}$, a secondary increase is observed starting at $155 \mathrm{u} / \mathrm{q}$ up to the mass detection limit $200 \mathrm{u} / q$. The most intense ion at $26 \mathrm{u} / \mathrm{q}$ is attributed to $\mathrm{CN}^{-}$(Vuitton et al. 2009). The other cyano group anions, $\mathrm{C}_{3} \mathrm{~N}^{-}$and $\mathrm{C}_{5} \mathrm{~N}^{-}$, are detected at 50 and $74 \mathrm{u} / \mathrm{q}$, respectively. Early work by Vuitton et al. (2009) suggested that $\mathrm{CN}^{-}$was mainly formed via DEA of $\mathrm{HCN}$ resulting from supra-thermal electron impact. More recently, however, Mukundan \& Bhardwaj (2018) and Vuitton et al. (2018) used updated DEA cross sections of $\mathrm{HCN}$, resulting in proton transfer between $\mathrm{H}^{-}$and $\mathrm{HCN}$ (Reaction 1) as the major pathway to $\mathrm{CN}^{-}$formation. $\mathrm{H}^{-}$is mainly produced through DEA of $\mathrm{CH}_{4}$ (Mukundan \& Bhardwaj 2018).

$$
\mathrm{H}^{-}+\mathrm{HCN} \longrightarrow \mathrm{CN}^{-}+\mathrm{H}_{2} \text {. }
$$

The main pathways for heavier species (Biennier et al. 2014; Dobrijevic et al. 2016; Mukundan \& Bhardwaj 2018; Vuitton et al. 2018) are given below. Mukundan \& Bhardwaj (2018) found REA to be the main production pathway to $\mathrm{C}_{3} \mathrm{~N}^{-}$due to differences in the neutral profiles used in both models.

$$
\begin{aligned}
& \mathrm{CN}^{-}+\mathrm{HC}_{3} \mathrm{~N} \longrightarrow \mathrm{C}_{3} \mathrm{~N}^{-}+\mathrm{HCN}, \\
& \mathrm{CN}^{-}+\mathrm{HC}_{5} \mathrm{~N} \longrightarrow \mathrm{C}_{5} \mathrm{~N}^{-}+\mathrm{HCN}
\end{aligned}
$$

These mass patterns are consistent with the ELS distributions $>20 \mathrm{w} / q$ (Figure 1, bottom panel) notably at $26 \mathrm{w} / q$. At 35-40 $\mathrm{u} / q$, we note an intermediate peak not reported previously in the ELS data, matching our mass group 3 surprisingly well. This further peak is only discernable intermittently at high Titan altitudes and is not observed during all encounters (e.g., it is absent in the T40 spectrum taken at $1244 \mathrm{~km}$ in Desai et al. 2017). The $50 \mathrm{w} / q$ peak is also consistent with the $45-70 \mathrm{w} / \mathrm{q}$ group present in the ELS 
T18 18:55:22 UT Ingress
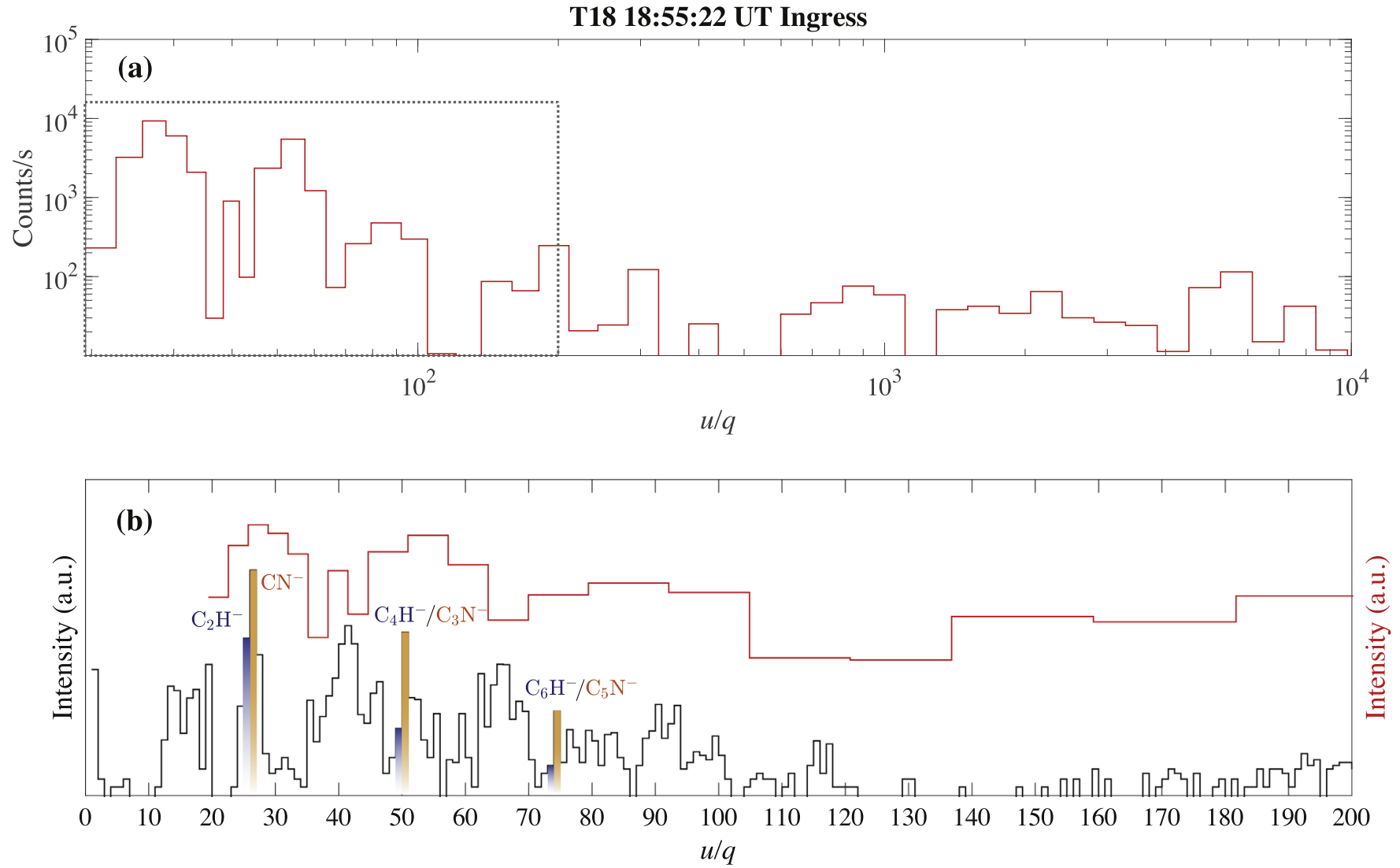

Figure 1. (a) CAPS-ELS mass/charge ingress spectrum taken during the T18 ingress encounter at $\sim 1235 \mathrm{~km}$. The dotted box represents the mass range plotted in the lower panel. (b) Comparison between the CAPS-ELS spectrum (red) and the registered experimental spectrum (black) taken in an $\mathrm{N}_{2}: \mathrm{CH}_{4} 95: 5 \%$ mixture (up to $200 u / q$ ), both shown in arbitrary intensity units. The bottom panel vertical axes are in log scale. Predicted species by Vuitton et al. (2009), Dobrijevic et al. (2016), Desai et al. (2017), and Mukundan \& Bhardwaj (2018) are also shown. The blue marks correspond to the hydrocarbon anions $\mathrm{C}_{2} \mathrm{H}^{-}, \mathrm{C}_{4} \mathrm{H}^{-}$, and $\mathrm{C}_{6} \mathrm{H}^{-}$at 25,49 , and $73 u / q$, respectively. The N-bearing anions $\mathrm{CN}^{-}, \mathrm{C}_{3} \mathrm{~N}^{-}$, and $\mathrm{C}_{5} \mathrm{~N}^{-}$at 26,50 , and $74 \mathrm{u} / q$, respectively, are labeled in orange.

Table 1

Broad Mass Groups from 1 to $200 u / q$ Defined by Wellbrock et al. (2013; Updated from Coates et al. 2007) Obtained from All of the First 34 Encounters

\begin{tabular}{|c|c|c|c|c|c|}
\hline \multicolumn{2}{|c|}{ Wellbrock et al. (2013) } & \multicolumn{2}{|c|}{ This Study } & \multicolumn{2}{|c|}{ This Study } \\
\hline \multirow[b]{2}{*}{$\begin{array}{l}\text { Mass } \\
\text { Groups }\end{array}$} & \multirow[b]{2}{*}{$u / q$} & \multicolumn{2}{|c|}{$\begin{array}{c}\text { Mass Groups (CAPS } \\
\text { Resolution) }\end{array}$} & \multicolumn{2}{|c|}{$\begin{array}{c}\text { Mass Groups } \\
\text { (Experimental } \\
\text { Resolution) }\end{array}$} \\
\hline & & $\begin{array}{l}\text { Mass } \\
\text { Groups }\end{array}$ & $u / q$ & $\begin{array}{l}\text { Mass } \\
\text { Groups }\end{array}$ & $u / q$ \\
\hline 1 & $12-30$ & 1 & $13-31$ & 1 & $11-18$ \\
\hline 2 & $30-55$ & 2 & $37-61$ & 2 & $23-34$ \\
\hline 3 & $55-95$ & 3 & $67-102$ & 3 & $35-$ \\
\hline 4 & $95-130$ & 4 & $115-121$ & 4 & $47-55$ \\
\hline 5 & $130-190$ & 5 & 169-200 & 5 & $56-71$ \\
\hline 6 & $190-625$ & & & 6 & $72-85$ \\
\hline \multirow[t]{3}{*}{7} & $625+$ & & & 7 & $87-1$ \\
\hline & & & & 8 & $104-122$ \\
\hline & & & & 9 & 150 \\
\hline
\end{tabular}

Note. These mass groups are qualitatively compared with groups defined from the experimental spectrum degraded to the CAPS resolution and the experimental spectrum from Figure 1 at much higher resolution.

spectrum. For larger mass species, it is noteworthy to point out that anions could be present at nearly every mass-per-unit charge of the spectrum given the continuous distribution of ELS over this mass range. At higher masses $(>70 \mathrm{w} / \mathrm{q})$, the laboratory spectrum further seems to match the ELS data at 70-90 and 110-120 $\mathrm{u} / \mathrm{q}$, which were characterized by Desai et al. (2017). A further increase in intensity starting at $140-150 \mathrm{~W} / \mathrm{q}$ is seen in both spectra, although the low ion signal currently renders the interpretation difficult.

\subsection{Spectra Analysis of Light and Intermediate $\mathrm{N}$-rich Anions}

Figure 2 shows the same experimental spectrum as in Figure 1 (bottom panel) with attributions of species $<100 \mathrm{u} / q$. Unexpected intense peaks stand out at 41,65 , and $66 \mathrm{u} / q$. Horvath et al. (2010a), who used a point-to-plane corona discharge at higher pressure, putatively assigned the peaks at 41 and $65 u / q$ to the diazirinyl $\mathrm{CHNN}^{-}$and dicyanomethanide $\mathrm{C}_{3} \mathrm{HNN}^{-}$anions, respectively. Other species that could correspond to these peaks according to the NIST are $\mathrm{C}_{2} \mathrm{H}_{3} \mathrm{~N}^{-}, \mathrm{C}_{3} \mathrm{H}_{5}^{-}$, and $\mathrm{C}_{5} \mathrm{H}_{5}^{-}$. Comparisons with tholin signatures and gas phase pathways are detailed hereafter, and confirm the attributions by Horvath et al. (2010a). Note the presence of a peak at $19 \mathrm{u} / q$, which likely corresponds to a fluorine $\mathrm{F}^{-}$ contamination. The presence of $\mathrm{F}^{-}$is presumably due to polytetrafluoroethylene (PTFE) from the temperature probe sheaths located near the polarized electrode in the reactor. This signal appears later over the accumulation, indicating that its contamination does not affect the overall signal of the spectrum. Also in this mass group, NH3 is inferred by the attribution of $\mathrm{NH}_{2}^{-}$at $16 \mathrm{u} / \mathrm{q}$ (Horvath et al. 2010b, 2011).

$\mathrm{CHNN}^{-}$can either be in a cyclic four- $\pi$ electron conformer or as an open biradical isomer (Gordon \& Kass 1995). These diazo 


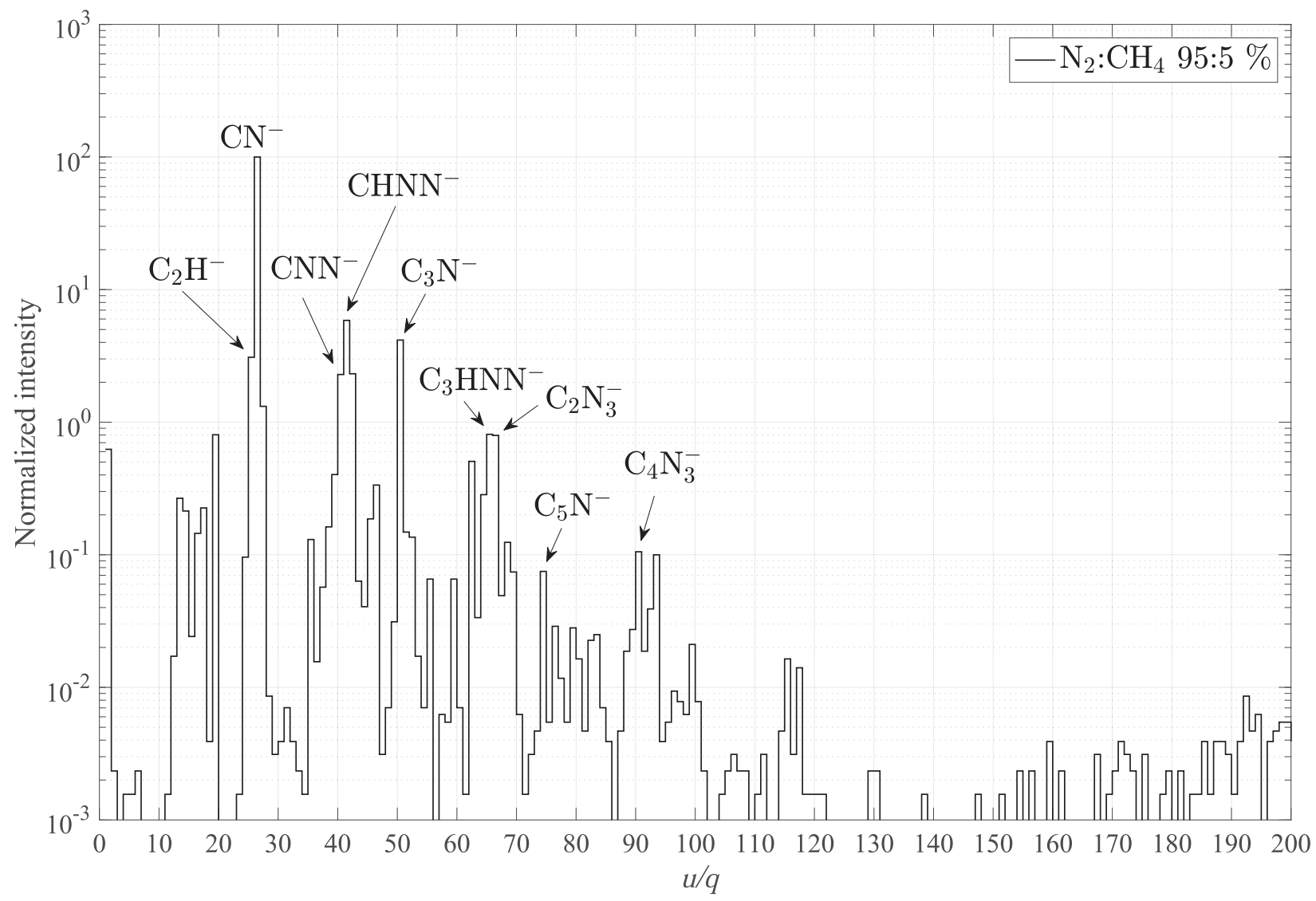

Figure 2. Registered mass spectrum of anions detected in an $\mathrm{N}_{2}: \mathrm{CH}_{4} 95: 5 \%$ plasma discharge, over 1-200 u/q, accumulated over 325 scans. Tentative attributions are shown for the major peaks.

isomer compounds are stable and can contain nitrogen-nitrogen double bonds (Kroeker \& Kass 1990; Gordon \& Kass 1995).

Current photochemical models largely account for nitrile incorporation of products containing only one nitrogen atom. Diazo and triazo species however, are not taken into account and their implications on the gas phase chemistry are poorly understood with respect to the nitrogen-rich tholins. Two previous studies by Gautier et al. (2011) and Cunha De Miranda et al. (2016) on the gas phase and solid tholin material produced in the PAMPRE reactor can be clues to this conundrum. Gautier et al. (2011) first identified $\mathrm{C}_{4} \mathrm{H}_{3} \mathrm{~N}_{5}$ (Tetrazolo[1,5-b]pyridazine) as the main aromatic gas phase product using gas chromatography. This heteroaromatic compound contains multiple single- or double-bonded nitrogen atoms. Furthermore, Cunha De Miranda et al. (2016) revealed the presence of heteroaromatic structures present in tholins such as triazole rings $\left(\mathrm{C}_{2} \mathrm{H}_{3} \mathrm{~N}_{3}\right)$. This compound, along with the cyclic diazirine c- $\mathrm{CH}_{2} \mathrm{~N}_{2}$ or cyanamide $\mathrm{H}_{2} \mathrm{~N}-\mathrm{CN}$, were shown to be strong candidates for the observed $\mathrm{N}=\mathrm{N}$ patterns. These isomers may indeed contain doubly bonded nitrogen atoms, which may account for the direct incorporation of $\mathrm{N}_{2}$ into tholins. Such N-rich patterns can be directly linked with the anions assigned here. The diazo and triazo radicals attributed in Figure 2 could indeed serve as important intermediates for the heterogeneous chemistry observed in tholins. Nitrogen incorporation into tholins may thus be facilitated by the potential presence of these nitrogen-rich (diazo and triazo) compounds in the gas phase.

Furthermore, the putative presence of intermediate species such as $\mathrm{CHNN}^{-}(41 u / q)$ could contribute more or less significantly to the overall $35-60 \mathrm{u} / \mathrm{q}$ mass grouping to which Desai et al. (2017) found a nominal mass center of $49 u / q$, within the $2 \sigma$ uncertainty, near closest approach. Nonattributed intermediate compounds formed seen here at high altitudes could potentially still be present in the ELS continuum at lower altitudes. Therefore, such a mass-over-charge shift to slightly lower values could indicate the presence of these intermediate compounds falling within the fitted distribution.

In spite of currently limited knowledge of diazo anion chemistry, we propose here mechanisms describing the putative presence of $\mathrm{CNN}^{-}$and $\mathrm{CHNN}^{-}(40$ and $41 \mathrm{u} / q$ ) or their possible isomers $\mathrm{NHCN}^{-}$and $\mathrm{NCN}^{-} . \mathrm{CH}_{2} \mathrm{CN}^{-}$could also be a candidate at $40 \mathrm{u} / \mathrm{q}$.

A candidate molecule within this mass range that is potentially available for the initiation of further pathways is $\mathrm{CH}_{2} \mathrm{~N}_{2}$ (e.g., He \& Smith 2014; Cunha De Miranda et al. 2016), for which three isomeric forms are considered here: diazomethane $\mathrm{CH}_{2} \mathrm{~N}_{2}$, cyclic diazirine $\mathrm{c}-\mathrm{CH}_{2} \mathrm{~N}_{2}$, and cyanamide $\mathrm{H}_{2} \mathrm{~N}-\mathrm{CN}$. $\mathrm{CH}_{2} \mathrm{~N}_{2}$ was previously excluded from the composition of tholins by Cunha De Miranda et al. (2016), while both cyclic diazirine and cyanamide have been identified among several nitrogenous prebiotic organic compounds present in tholins (He \& Smith 2013, 2014; Cunha De Miranda et al. 2016). Formation of linear $\mathrm{CH}_{2} \mathrm{~N}_{2}$ (diazomethane) following $1 \mathrm{CH}_{2}+\mathrm{N}_{2} \longrightarrow \mathrm{CH}_{2} \mathrm{~N}_{2}$ was shown by Braun et al. (1970) to be significant only for high pressures that are neither relevant to our experimental setup nor to Titan's upper atmosphere conditions. $\mathrm{HCN}$ and $\mathrm{NH}_{3}$ alone were suggested to contribute to the formation of cyanamide $\mathrm{H}_{2} \mathrm{~N}-\mathrm{CN}$ (and its dimer dicyanodiamide $\mathrm{C}_{2} \mathrm{H}_{4} \mathrm{~N}_{4}$ ) according to Reaction 4 
(He \& Smith 2013). The cyanamide isomer can also go through a number of low-energy EA or DEA reactions (Reactions 5, 6 and Tanzer et al. 2015).

$$
\begin{gathered}
\mathrm{HCN}+\mathrm{NH}_{3} \longrightarrow \mathrm{H}_{2} \mathrm{~N}-\mathrm{CN}+\mathrm{H}_{2}, \\
\mathrm{H}_{2} \mathrm{~N}-\mathrm{CN}+\mathrm{e}^{-} \longrightarrow \mathrm{NHCN}^{-}+\mathrm{H}(41 u / q), \\
\mathrm{H}_{2} \mathrm{~N}-\mathrm{CN}+\mathrm{e}^{-} \longrightarrow \mathrm{CNN}^{-}+\mathrm{H}_{2}(40 u / q) .
\end{gathered}
$$

Similar routes from the parent neutral diazirine $c-\mathrm{CH}_{2} \mathrm{~N}_{2}$ may also occur (Reactions 7 and 8).

$$
\begin{gathered}
\mathrm{c}-\mathrm{CH}_{2} \mathrm{~N}_{2}+\mathrm{e}^{-} \longrightarrow \mathrm{c}^{-} \mathrm{CH}_{2} \mathrm{~N}_{2}^{-}(42 u / q), \\
\mathrm{c}-\mathrm{CH}_{2} \mathrm{~N}_{2}+\mathrm{e}^{-} \longrightarrow \mathrm{CNN}^{-}+\mathrm{H}_{2}(40 u / q) .
\end{gathered}
$$

In group 5, the other diazo anion $\mathrm{C}_{3} \mathrm{HNN}^{-}$(dicyanomethanide) attributed to the peak at $65 \mathrm{u} / \mathrm{q}$, following Horvath et al. (2010a), has an intensity of an order of magnitude greater than $\mathrm{C}_{5} \mathrm{~N}^{-}$. It is accompanied by a second intense peak at $66 \mathrm{u} / q$. This mass can correspond to two anions, $\mathrm{C}_{4} \mathrm{H}_{4} \mathrm{~N}^{-}$and $\mathrm{C}_{2} \mathrm{~N}_{3}^{-}$ (the pyrrolide anion and dicyanamide, respectively). $\mathrm{C}_{4} \mathrm{H}_{4} \mathrm{~N}^{-}$ was tentatively attributed by Horvath et al. (2010a), whose parent neutral is pyrrole $\mathrm{C}_{4} \mathrm{H}_{5} \mathrm{~N}$. Given the previous detections of pyrrole and other heterocyclic aromatic compounds in this and other similar plasma discharge experiments, as well as in tholin material (e.g., McGuigan et al. 2006; Gautier et al. 2011; He \& Smith 2014; Mahjoub et al. 2016), such an ion can be a candidate for $66 u / q$. However, Carrasco et al. (2009) carried out analyses of the soluble fraction of tholins and measured charged ionic species by collision-induced dissociation (see also Somogyi et al. 2012). They found recurrent ionic fragments at $66 u / q$ which, given its fragmentation patterns observed in negative ion mass spectrometry, revealed dicyanamide $\mathrm{C}_{2} \mathrm{~N}_{3}^{-}$to be a better candidate at this mass-to-charge ratio. Therefore, we attribute the gas phase $\mathrm{N}$-containing carbanion precursor $\mathrm{C}_{2} \mathrm{~N}_{3}^{-}$as a likely compound at the $66 \mathrm{u} / \mathrm{q}$ peak. Interestingly, this compound has a v-shaped bent conformation $\left(\mathrm{C}_{2 V}\right)$ with a permanent dipole moment, and was found to be unreactive and extremely stable, potentially existing in cold regions of the ISM (Yang et al. 2011; Nichols et al. 2016). Furthermore, it was shown by Carrasco et al. (2009) and Somogyi et al. (2012) that $\mathrm{C}_{2} \mathrm{~N}_{3}^{-}$was part of a fragmentation pattern involving $\mathrm{HCN}, \mathrm{C}_{2} \mathrm{H}_{2}$, and $\mathrm{NH}_{2} \mathrm{CN}$ formal additions. The attribution here of $\mathrm{C}_{2} \mathrm{~N}_{3}^{-}$and its relative intensity in the gas phase sustains its important role as a precursor "seed" as proposed in the aforementioned studies. This N-containing carbanion may indeed play an important role in the polymerization growth of tholins and large gas phase N-rich precursors (Carrasco et al. 2009; Somogyi et al. 2012).

Finally, $\mathrm{C}_{2} \mathrm{~N}_{3}^{-}$(along with $\mathrm{C}_{4} \mathrm{~N}_{3}^{-}$) has no substantial reactivity with protons, and its stability in hydrogen and $\mathrm{N}$-containing carbanion-rich environments may make it a viable candidate as a gas phase precursor (Bierbaum 2011). Given the bent and polar structure of $\mathrm{C}_{2} \mathrm{~N}_{3}^{-}$, future rotational spectrum analyses of this compound should help in its potential detection in planetary atmospheres and the ISM.

\section{Summary}

Our current understanding of the growth pathways of anions and their role as precursors to haze macromolecules in Titan's upper atmosphere is limited. Measurements performed by CAPS-ELS revealed unidentified compounds up to $13,800 \mathrm{u} / \mathrm{q}$ in the ionosphere. State-of-the-art photochemical models have attributed only a few of the first ions as carbon-chain anions
$\mathrm{CN}^{-} / \mathrm{C}_{3} \mathrm{~N}^{-}$and $\mathrm{C}_{2} \mathrm{H}^{-} / \mathrm{C}_{4} \mathrm{H}^{-}$. In order to further investigate the anion chemistry and composition responsible for this efficient growth, we conducted our first direct anion measurements with $u / q$ up to 200 in the PAMPRE dusty plasma discharge. Spectra were taken in an $\mathrm{N}_{2}: \mathrm{CH}_{4}$ 95:5\% gas mixture, representative of Titan's ionospheric conditions. The broad mass groupings obtained in the laboratory spectra are consistent with recent ELS data analyses. These results are obtained at a higher resolution than the ELS data and reveal new and abundant N-rich compounds. It is therefore plausible that some of these compounds may be present in Titan's ionosphere, given the difficulty in interpreting the continuous ELS data at higher masses. Notable peaks at 26, 41, 50, 65, and $66 \mathrm{u} / q$ are attributed to $\mathrm{CN}^{-}, \mathrm{CHNN}^{-}, \mathrm{C}_{2} \mathrm{~N}_{3}^{-}$, and $\mathrm{C}_{3} \mathrm{HNN}^{-}$, $\mathrm{C}_{2} \mathrm{~N}_{3}^{-}$, respectively. In particular, the diazo and triazo compounds appear to be important $\mathrm{N}$-rich anion precursors to tholin formation. Such a nitrogen incorporation into Titan tholins is compatible with $\mathrm{N}=\mathrm{N}$ patterns seen in tholins. Anion chemistry may therefore be a privileged route for $\mathrm{N}$-bearing carbanions to form large compounds and ultimately to be incorporated into the compositional structure of tholins. Lastly, these results also call for further experimental, theoretical and observational studies working comprehensively to decipher the unsuspected and complex anion chemistry of Titan's ionosphere.

The authors wish to thank the two anonymous reviewers who participated in the improvement of the manuscript. We also thank V. Mukundan, Dr. E. Sciamma-O'Brien, and Dr. J. Westlake for insightful discussions. D.D., N.C., J.B., and L.V. acknowledge financial support by the European Research Council Starting Grant PrimChem, grant agreement No. 636829. R.T.D. was supported by NERC grant NE/P017347/1. A.J.C. and A.W. acknowledge support from the STFC consolidated grant to UCL-MSSL ST/ N000722/1, and ESA and UKSA for CAPS-ELS operations support.

\section{ORCID iDs}

David Dubois (1) https://orcid.org/0000-0003-2769-2089 Nathalie Carrasco (1) https://orcid.org/0000-0002-0596-6336 Jérémy Bourgalais (i) https://orcid.org/0000-0003-4710-8943 Ludovic Vettier (1) https://orcid.org/0000-0002-2027-0943 Ravindra T. Desai (1) https://orcid.org/0000-0002-2015-4053 Andrew J. Coates (1) https://orcid.org/0000-0002-6185-3125

\section{References}

Ågren, K., Edberg, N. J. T., \& Wahlund, J. E. 2012, GeoRL, 39, L10201 Biennier, L., Carles, S., Cordier, D., et al. 2014, Icar, 227, 123 Bierbaum, V. M. 2011, in IAU Symp. 280, The Molecular Universe, ed. J. Cernicharo \& R. Bachiller (Cambridge, Cambridge Univ. Press), 383 Bourgalais, J., Jamal-Eddine, N., Joalland, B., et al. 2016, Icar, 271, 194 Braun, W., Bass, A. M., \& Pilling, M. 1970, JChPh, 52, 10

Brünken, S., Gupta, H., Gottlieb, C. A., et al. 2007, ApJL, 664, L43 Carrasco, N., Schmitz-Alfonso, I., Bonnet, J. Y., et al. 2009, JPCA, 113, 11195 Coates, A. J., Crary, F. J., Lewis, G. R., et al. 2007, GeoRL, 34, L22103 Coates, A. J., Wellbrock, A., Lewis, G. R., et al. 2009, P\&SS, 57, 1866 Cunha De Miranda, B., Garcia, G. A., Gaie-Levrel, F., et al. 2016, JPCA, 120, 6529

Desai, R. T., Coates, A. J., Wellbrock, A., et al. 2017, ApJL, 884, L18

Dobrijevic, M., Loison, J. C., Hickson, K. M., \& Gronoff, G. 2016, Icar, 268, 313

Dubois, D., Carrasco, N., Petrucciani, M., et al. 2019, Icar, 317, 182

Gautier, T., Carrasco, N., Buch, A., et al. 2011, Icar, 213, 625

Gordon, M. S., \& Kass, S. R. 1995, JPhCh, 102, 7100

He, C., \& Smith, M. A. 2013, Icar, 226, 33 
He, C., \& Smith, M. A. 2014, Icar, 243, 31

Horvath, G., Aranda-Gonzalvo, Y., Mason, N. J., et al. 2010a, EPJAP, 49, 13105

Horvath, G., Krcma, F., Polachova, L., et al. 2011, EPJAP, 53, 11001

Horvath, G., Mason, N. J., Polachova, L., et al. 2010b, Plasma Chemistry and Plasma Processing, 30, 565

Kroeker, R. L., \& Kass, S. R. 1990, JAChS, 7, 9024

Lavvas, P., Yelle, R. V., Koskinen, T., et al. 2013, PNAS, 110, 2729

Mahjoub, A., Schwell, M., Carrasco, N., et al. 2016, P\&SS, 131, 1

McGuigan, M., Waite, H. J., Imanaka, H., \& Sacks, R. D. 2006, Journal of Chromatography A, 1132, 280

Millar, T. J., Walsh, C., Field, T. A., et al. 2017, ChRv, 117, 1765

Mukundan, V., \& Bhardwaj, A. 2018, ApJ, 856, 168

Nichols, C. M., Wang, Z. C., Yang, Z., et al. 2016, JPCA, 120, 992
Somogyi, Á., Smith, M., Vuitton, V., et al. 2012, IJMSp, 316, 157

Szopa, C., Cernogora, G., Boufendi, L., Correia, J. J., \& Coll, P. 2006, P\&SS, 54, 394

Tanzer, K., Pelc, A., Huber, S. E., et al. 2015, JChPh, 142, 034301

Vuitton, V., Lavvas, P., Yelle, R. V., et al. 2009, P\&SS, 57, 1558

Vuitton, V., Yelle, R. V., Klippenstein, S., et al. 2018, Icar, in press (https:// www.sciencedirect.com/science/article/pii/S0019103517307522)

Waite, J. H., Young, D. T., Cravens, T. E., et al. 2007, Sci, 316, 870

Wang, Z. C., Bierbaum, V. M., Alcaraz, C., et al. 2016, JChPh, 144, 214304

Wang, Z. C., Cole, C. A., Demarais, N. J., et al. 2015, JAChS, 137, 10700

Wellbrock, A., Coates, A. J., Jones, G. H., Lewis, G. R., \& Waite, J. H. 2013 , GeoRL, 40, 4481

Yang, Z., Cole, C. A., Martinez, O., Jr., et al. 2011, ApJ, 739, 19

Zabka, J., Romanzin, C., Alcaraz, C., et al. 2012, Icar, 219, 161 